\title{
THE WEARINESS OF THE FLESH: REFLECTIONS ON THE LIFE OF THE MIND IN AN ERA OF ABUNDANCE
}

\author{
Paul B. Gandel \\ Vice Provost for Info Svcs \& Dean, University Libraries \\ University of Rhode Island \\ Kingston, RI \\ (401) 874-4599 \\ gandel@uri.edu \\ Richard N. Katz \\ Vice President \\ EDUCAUSE \\ 4772 Walnut Street \\ Suite 206 \\ Boulder, CO 80301-2538 \\ Phone: (303) 939-0319; Fax: (303) 440-0461 \\ rkatz@educause.edu
}

\begin{abstract}
The invention of the printing press reduced higher education's learning-resource scarcity. Access to learning increased, and this democratization of education indirectly contributed to the idea of political democracy in the western world. As part of these political changes, equilibrium was sought between the supply of expertise needed to promote prosperity and the demand for such expertise. This equilibrium has been elusive as the world economy shifts to a reliance on intellectual capital. To complicate matters, we now live in a world of staggering information abundance. How do we mange such boundless information? One answer may lie in viewing the social character of information (how information is used) as fundamental in setting information management agendas. This article presents a holistic approach to information management as one strategy to create effective management of information that starts with the individual and ends with collective knowledge and wisdom.
\end{abstract}

\section{KEY WORDS}

Knowledge economy, information abundance, information management, information ecology, personal digital repositories

\section{INTRODUCTION}

Elsewhere in this volume, William Graves and Carol Twigg call our attention, appropriately, to issues of scarcity. By focusing our attention on the "three As" of accessibility, affordability, and accountability, these authors correctly focus our attention on one of the great dilemmas of the so-called knowledge-driven 
era. This dilemma, of course, is the disequilibrium between the supply of knowledge workers and the increasing global demand for their services. This imbalance focuses our attention on issues of scarcity; and scarcity, in turn, forces our attention on educational access and affordability (supply and availability), on efficiency, productivity, (resource utilization), and accountability.

The urgency of the issues associated with access, affordability, and accountability has blunted our attention on a fourth A: abundance - though in fairness, abundance is really one subtext in a conversation about educational supply. Abundance deserves elevation and discussion in this issue because on some levels, the history of human learning can be described in terms of scarcity, and because the realpolitik of the web and web-based learning provides an important opportunity to rethink many of our core assumptions about the nature of teaching and learning and about the purposes of the college or university.

\section{A HISTORY OF SCARCITY}

Higher education's history is a history of scarcity - scarcity of learning resources such as educational facilities, libraries, and laboratories and scarcity of experts: masters and professors. Prior to the invention of moveable type, literacy and learning were placed in the service of the secular or ecclesiastical ruling elites. Sacred and secular texts were copied by hand and stored in imperial palaces or monastic scriptoria for protection from both the elements and prying eyes. The diffusion of knowledge in an era of scarcity was necessarily slow and highly controlled. Access to learning and knowledge was mediated by privilege and social standing, and literacy was both limited and rationed because of the prevailing technologies (hand copying and illuminating manuscripts) and as a means of enforcing social control.

The complexity of ruling and taxing nation-states necessitated the broadening of educational access in secular matters, creating an environment conducive to the construction of the great European universities at Bologna, Pisa, Oxford, Cambridge, and Paris. Still, social control was not to be sacrificed and access continued to be confined to the second and third sons of the ruling elite.

Gutenberg's invention of the printing press fostered literacy (e.g., access), democratized learning, and thereby lessened the political authority of church and state in Europe. Among other things, the impact of this invention on the political economy of scarcity is credited with the Protestant Reformation. The spread of literacy, through the increase of experts and information resources, indirectly contributed as well to the French Revolution, the American Revolution, and the spread of the idea of political democracy in Western Europe and the New World.

The history of Western higher education since the French Revolution has been dominated by at least seven epochal influences:

(1) The Jeffersonian ideal that equated higher education with effective citizenship and the viability of the democratic system of government;

(2) The U.S. Morill Act of 1862, creating grants of federal land to U.S. states for the purpose of creating public universities that would freely admit students for the purpose of study in the agricultural and mechanical (engineering) arts-variations on this act appear in Canada and some European and Commonwealth countries;

(3) The creation of the first research university in Berlin (Humboldt University) and the replication of this model in the U.S. (Johns Hopkins University);

(4) The U.S. community college movement; 
(5) The creation of the megaversity, exemplified by the Open University;

(6) The successful private-market capitalization, standardization, and globalization of higher education exemplified the University of Phoenix; and

(7) The partially successful integration of synchronous and asynchronous online instructional techniques with the proliferation, controlled and uncontrolled, of online resources.

All of these developments reflect inventions. Institutions were designed to foster equilibrium between the supply of expertise needed to promote social and economic prosperity and the demand for such expertise. Equilibrium, of course, has proved to be elusive as the world economy shifts, growing from its reliance on the traditional factors of production such as land, labor, and financial capital to factors increasingly associated with renewable components such as intellectual capital.

\section{AN ERA OF INFORMATION ABUNDANCE}

The proliferation of computers, networks, and networked information creates a new dilemma. In this dilemma, access to information is, or can be forecast to be, relatively easy, inexpensive, widespread, and democratic. In essence, information and the tools needed to place information in the service of education are accessible. Of course, even 3,000 years ago, King Solomon reminded us that "of making many books, there is no end; and much study is a weariness of the flesh [1]." The dilemma of the first decades of the knowledge-driven era is that of a new abundance and of a new and perhaps growing disequilibrium between the raw materials of learning production (e.g., information resources) and the other factors of learning production (tutors, professors, intelligent learning environments, asynchronous learning programs, online mediation techniques, and the like). Further, our current and prospective era of information abundance will challenge many of our basic assumptions and practices about safeguarding, protecting, filtering, preserving, evaluating, purging, describing, cataloguing, and vetting information pursuant to the purposes of teaching, learning, and scholarship.

So, while humans have long bemoaned searching for needles in haystacks, why does this issue of information abundance deserve particular attention here and now? There are four reasons.

First, the shift from an industrial to a knowledge economy recognized by Daniel Bell as early as 1973 [2] has begun, is accelerating rapidly, and is now accepted in principle by most. The economies of many postindustrial nations are dominated by (1) information technology and telecommunications; (2) financial services; (3) entertainment, publishing, news, and other media; and (4) pharmaceutics and biotechnology. These industries do not depend for their success on labor or land, but instead on intellectual and financial capital. They are quintessentially knowledge industries dependent on information technology, on having or restricting access to the right information at the right time, and on managing information flows.

Second, the economics of semiconductor and related manufacturing should force us to reassess our thoughts about scarcity and abundance. Moore's Law, which posits the doubling of semiconductor performance at any constant price over any 18-month period, has been validated in the commercial market for more than 20 years. Further, a spate of related laws has been coined to account for and anticipate the doubling of storage capacity, bandwidth, and other elements of the IT infrastructure. In essence, a basic desktop computer with significant local storage now costs no more than the ubiquitous color TV. High-speed internet access is widely available in most cities and in many university towns, at prices that compare with premium cable television service. In short, access to the electronic tools of modern learning probably now compare favorably with the cost of textbooks and increasingly subsume the costs of some licensed resources such as course materials, telephone, television, and others. These 
costs will likely continue to decline dramatically in relation to performance.

Third, information integration is becoming the norm. If the first half century's history of computing in higher education was the history of developing standalone and institutionally-based systems to support higher education's myriad administrative details such as paying people, accounting for money and things, issuing parking fines, tracking library books, fining, billing, registering people for class, and allocating classrooms, the next half century is likely to be characterized by the standardization of these applications; integration of these applications with one another, and shift of attention, invention, and investment to systems designed to foster learning productivity and outcomes.

Since 1997, U.S. colleges and universities alone have spent more than $\$ 5$ billion to modernize and standardize their core administrative information systems. New techniques and standards such as XML and Web Services are being investigated and deployed to further the moves toward standardization and interoperability. Already, two-thirds of U.S. colleges and universities have implemented one or more course management systems (CMS) to introduce automation and standardize the delivery of instruction. New and improving technologies and techniques for storing, mining, analyzing, and presenting data and information are bringing together textual, aural, visual, and other sources in new ways. Further, breakthroughs in animation, scientific visualization, virtual reality, and simulation are making it possible for people to interact with information in fundamentally new ways.

Fourth, one underlying principle of the knowledge-driven era is that education is a lifelong endeavor and may - only occasionally — be mediated by the traditional artifacts of our historical learning experiences: places, professors, age-normed peer learners, degrees. The shift from an age-specific learning expectation to a lifelong expectation is already reshaping the marketplace for teaching and learning. New assessments of educational outcomes, new markers of educational attainment, new suppliers, and new methods of institutional accreditation are appearing and evolving as we scramble to mediate supply and demand for knowledge and learning.

\section{A FUTURE OF NEARLY UNIMAGINABLE ABUNDANCE}

In many ways, the markets for knowledge and learning are evolving like those for food. From a planetary perspective, we have the capacity to produce enough food to sustain human life in a reasonable fashion. The problems of nutrition and world hunger relate more to issues related to distribution, global politics and economics, education, and other complex factors. With regard to information, knowledge, and learning, the future is nearly unimaginable. As the costs of electronic storage continue to plummet, the capacity will be created for everyone who so chooses to capture, make visible, disseminate, and preserve every moment of our lives. Our capacity to create a comprehensive digital record of our work and life experiences will make earlier innovations such as desktop publishing look like rounding errors.

The new potential will influence institutional and individual behaviors, expectations, and experiences immensely. Before the invention of photography, for example, only the rich could afford to document their existence through commissioning a painting or sculpture. The invention of photography made it possible for everyday people to document themselves in the course of their everyday lives. Today, reality TV and webcams and now cell phones record, store, and broadcast the minutiae of some people's lives. Weblogs reflect early attempts to organize our personal experiences for the purpose of sharing those experiences with others. In the next decade, the recording, storage, and broadcast of the minutiae of everyone's life will become technically and economically feasible. Seizing this possibility will simply be a matter of choice. 
While the educational benefits of such capability may be arguable, it is less arguable that these capabilities will be available or that they will be used. Wild underestimates of the capacity of people to find uses for telephones or the PC at home or in offices are ascribed to the likes of Microsoft's Bill Gates and Digital's Ken Olson, and now make for humorous asides over drinks. The internet remained long the domain of the techies until the web opened that medium up for popular consumption.

The educational implications of staggering abundance - that is, the near-infinite individual recording, storage, and transmission capabilities - should in fact be argued in significant detail. For example, over 31 billion pieces of email are now exchanged daily [3]. While it is unlikely that we will accurately forecast, let alone manage, the impacts of massive information abundance, it is axiomatic that these impacts will magnify King Solomon's complaint beyond comprehension. These implications will be both institutional and pedagogical.

\section{THE MANAGEMENT OF BOUNDLESS INFORMATION}

Economists will quickly remind you that "almost free" isn't free, and anyone who has been responsible for managing an institution's stock of technology, software licenses, licenses for library content, and so forth will quickly add that indeed while costs per MIPS, per message transmitted, per gigabyte, or per lookup have all plummeted, the total costs of maintaining this new environment have skyrocketed. Quietly, higher education technology providers are engaged in discussion about what IT services and what service levels to maintain. Some are withdrawing from the decreasingly sustainable provision of telephone services for students in college housing, while others ponder the potential of offering electronic mail services to alumni, parents, and other stakeholders in addition to current students, faculty, and staff. Cliff Lynch points out that we now have the capacity to make all our courses "visible" as more and more course material gets produce in digital form and is stored on institutional computers [4]. MIT has taken the first very visible step in this direction by making all its course material available to the world through its Open Knowledge Initiative. The question then becomes how much almost-free disk space should be allocated to members of the community, for how long, and for what purposes?

Institutions are becoming more and more sophisticated users of the information they possess, and they will need to get progressively better at data modeling, warehousing, mining, and reporting. The potential nuclear meltdown at Three Mile Island illustrates this point. Meltdown nearly occurred not because of the lack of information but because technicians did not attend to the right information. As Christopher Burns points out, "The crisis at Three Mile Island dramatically illustrates how disaster can result if information quantity is used as a substitute for information quality [5]." Similarly, the tragic events of 9/11 also illustrate, in part, the problem of too much information. Almost everyone associated with the investigation of possible intelligence failures agrees that the failure to prevent the attacks stemmed not from the lack of intelligence information, but rather from the failure to recognize this information and to act on it in a coordinated fashion.

The clash of cultures within the data management professions further exacerbates the development of effective institutional information management strategies. Technologists view the problem from the perspective of creating greater capacities for digital storage or creating better search engines. Librarians are often focused primarily on the acquisition of information external to the institution. Moreover, the systems they have created are built on preservation and scarcity, not abundance. Archivists and records managers, on the other hand, are geared to making policy decisions about what's important. However, the scope of their responsibility never expanded beyond official and typically paper documents. Furthermore, they are too often focused on the evidential qualities of records rather than the informational content of records that can be used for decisions and actions [6]. 
The personal counterpart to the institutional data management dilemma described at Three Mile Island is described richly by R. L. Ackoff in his article Management Misinformation Systems. Ackoff found that students who were given only abstracts of journal articles performed better on exams than students who were assigned the reading of the entire article. Ackoff concludes, "I do not deny that most managers (people) lack a good deal of information that they should have, but I do deny that this is the most important information deficiency from which they suffer. It seems to me that they suffer from an overabundance of irrelevant information [7]."

\section{CREATING BOUNDARIES: THE ECOLOGY OF MANAGING INFORMATION}

In essence, what is being implied above is that information, knowledge, and wisdom are more than just the collection of bits within large data stores. Rather, it is the social character of information, that is, how information is used, that should become primary in setting our information management agendas. While the raw information of scholarship and learning is being collected at an astounding rate, it is also being lost or made unusable at an even more astounding rate. Therefore, we need to take a much more holistic approach that recognizes the interconnection of information resources and the individuals who create and use this information. A metaphor that has been used to describe this holistic approach is to view information systems as a form of ecosystem - an information ecology.

Nardi and O'Day define information ecology as a system of "people, practices, values, and technology in a particular local environment [8, p49]." For Davenport, information ecology puts "how people create, distribute, understand, and use information at its center [9, p5]." Both definitions focus on human activities and not technology as the core of an information system. The key is capturing not simply the data and information, but the contextual relationships and meanings people give to that information. These ideas, of course, can be traced to Vanevar Bush and his famous conceptualization of Memex. In 1945, Bush argued,

Our ineptitude in getting at the record is largely caused by the artificiality of systems of indexing. When data of any sort are placed in storage, they are filed alphabetically or numerically, and information is found (when it is) by tracing it down from subclass to subclass. It can be in only one place, unless duplicates are used; one has to have rules as to which path will locate it, and the rules are cumbersome. Having found one item, moreover, one has to emerge from the system and re-enter on a new path. The human mind does not work that way. It operates by association. With one item in its grasp, it snaps instantly to the next that is suggested by the association of thoughts, in accordance with some intricate web of trails carried by the cells of the brain [10].

The idea behind information ecology is that the basic elements are flows and nodes (think of flows as conduits and nodes as information stores) that are intertwined in the sense that one builds on the other. The dynamics of flows and nodes are not random, but are determined by the interaction of four dimensions: interdependency, change, timeboundness, and differentiation. More simply, an information ecology is defined as a system of people, practices, values, and technologies in a particular environment. The word ecology is important here, because it conveys the sense of urgency about the need to control our information ecologies "to inject our own values and needs into them so that we are not overwhelmed by some of our technological tools [8, p56]."

As Bush argues, too often in developing information systems, we expect information to fit into some preordained system such as the way we fit books into the Dewey Decimal System. Taking a more 
ecological approach to information systems calls for focusing instead on the way information is created and used - in many respects an approach not unlike the one used by traditional archivists, that is, traditional archival approaches that follow the principles of provenance and original order in building stores of information and data. Provenance is more about keeping intact the original intent, organizational order, and associational thinking of the creator reflecting the context in which the information was usedin other words, focusing on the individual creator and user of the information. Just as the study of ecological systems focuses first on the individual organisms, perhaps too the design of our information systems should first center on how individuals create and use information.

\section{A. Focusing on the Individual}

If we began with the premise that our information systems should be designed based on the individual, how would such a system work? First and foremost it would have to address individual information needs. For example, institutions that are beginning to create institutional digital depositories are finding it difficult to get professors to contribute documents and other materials to these depositories. Part of the problem may be the rigid organizational schemes designed to meet broadly based needs. The problem may also be that these systems were not designed specifically with the management of individual information needs in mind. It may in fact be unreasonable to expect a professor or university administrator to create specialized metatags to meet the requirements of institutional digital repository, especially if that activity is separate from the scholarly or work activity. On the other hand, what if we provided individuals the tools to easily create and share personal digital depositories designed to meet the productivity needs of the scholar, administrator, or student — systems designed to organize and facilitate their own research, work, or learning agenda?

These questions almost inevitably lead to an exploration of e-portfolios. If an e-portfolio is not simply a collection of material, but a collection of material with a purpose, it fulfills the best purposes associated with personal archives. That is, such collections mindfully built according to conscious choices about what to retain and what to discard form a knowledge base about an individual, what we will refer to as a personal digital repository. It is a repository that collects and synthesizes data and information the way an individual needs and uses that information. While the terms e-portfolio or content management system could be used to describe such a personal information system because it shares much with them from a technological perspective, we find personal digital repository a much more appropriate term because it reflects the specific purpose of such a system. Such repositories begin to fulfill Bush's prophesy of Memex: "a device in which an individual stores all his books, records, and communications, and which is mechanized so that it may be consulted with exceeding speed and flexibility. It is an enlarged intimate supplement to his memory [10]."

Personal digital repositories offer intriguing possibilities to bring together individual collected wisdom and knowledge built over time that can be shared with others. Imagine if researchers could not only shift through Einstein's own writings but also the writings of others that he collected over time and used as a basis for building his own ideas. Furthermore, imagine that researchers would also be able to trace the contextual relationships and references Einstein created among all this material. In some sense, it would be like looking over the shoulder of a great thinker and tracing the evolution of his thought process over time by exploring his personal knowledge store.

On the other hand, for years, CIOs have worked diligently to eliminate shadow systems so that all information might be kept in centralized and standardized repositories. Encouraging the development of personal digital depositories would require a change in our strategic focus. It also begs the question, What's to keep this from becoming the dreaded proliferation of disparate shadow information systems 
that CIOs have long worked to prevent? Therefore, what role if any does the community play in the articulation and enforcement of standards as regards such repositories or archives, what costs does this institution incur to support them, and what rights of access or ownership do institutions receive or grant vis-à-vis these portfolios? These broad policy questions don't even skim the surface of the myriad other more practical issues such as standards of authenticity for information in digital repositories, and so forth.

\section{B. Creating Institutional Repositories from the Bottom Up}

While the fear that personal digital depositories could become isolated silos of information is certainly real, a very different scenario can be envisioned. Recent developments such as weblogs and P2P technology demonstrate it's possible to build shared knowledge stores from the bottom up. Using networked models based on jointly shared and controlled resources, personal digital depositories could be viewed as the building blocks for creating collective knowledge stores of affinity groups and organizations. These self-governing groups could develop a set of standardized practices and approaches to building collective repositories from individual repositories over time. The tactics for collecting these aggregated resources could focus on how organizations and groups actually use these information resources. And, as in our scholarly community and our work environment, peer review and peer pressure could serve as the mechanisms for weeding the wheat from the chaff in these collective repositories.

This organic approach of building organizational digital repositories from the bottom up is very much in keeping with the ecological approach advocated by Davenport for institutional information repositories. In fact, Davenport sees it as the only viable organizational approach to manage the growing glut of information. According to Davenport, "A centralized highly engineered approach to this vast amount of information is clearly untenable. Even the most carefully maintained records are of no value unless they are used. Information management strategies that make every employee a records manager seems to be the only viable alternative $[9, \mathrm{p} 20] . "$

To facilitate navigation through the network of personal and collective digital repositories, metatools could be developed akin to web services. That is, tools could be built that would allow information repositories to advertise their availability in much the same way archivists develop tools to describe their collections. These are repository guides, summarizing the holdings, finding aids that detail the contents and an index that complements the provenance or arrangement as an aid to identifying relevant parts of the collections. Together, these tools would work to provide a broad overall view of the material as well as pointers to specific parts of the collection.

\section{Implementing an Information Collective}

Assuming that digital repositories could be built from the bottom up as part of a collective process of individual records management and knowledge creation, the questions then become: Where will all this information reside? How would they be linked? A special form of data storage would be needed. It would have to provide a permanent electronic address for the collection of digital bits making up the repositories, regardless of their physical location. In other words, it would serve as an electronic archival bucket that would provide a permanent electronic home for the repository. Permanent electronic locations would also facilitate creating links between repositories. Within the bucket, multiple formats and multiple internal organization schemes would have to be supported.

Work on such systems for the permanent storage of digital archival records is already under way. The DSpace system, from MIT, and Fedora are two examples of such digital repositories. The Tufts V.U.E. project demonstrates that it also possible to build tools and standards that allow for sharing of information 
as well as the associated contextual mapping of that information within the framework of a digital repository. While these tools are primarily aimed at creating institutional repositories, it may also be possible to use the same technical approach to create a full network of individual as well as group repositories, thus creating the nodes and flows necessary for a vibrant and effective ecological system of shared information and individual knowledge and wisdom.

\section{New Roles for the Information Professional}

Clearly, in a world of network information systems consisting of individual as well as collective digital repositories, the role of the information and technology specialists will need to change. Technologists will need to devise more transparent systems plans for convergence of systems and a convergence of information types. Instructional designers will need to support and educate the academic community about the benefits of gathering and sharing digital assets and learning objects. The librarian will have less of a role of organizing materials according to rigid standards and more of a role in developing flexible organizing principles for a variety of materials built on an underlying set of standard guidelines. Their focus will be less about organizing the material after the fact and more about teaching others how to organize their materials as they produce them. Records managers' roles will be in terms of the types of materials addressed and the overall information policy of the organization and needs of individuals within those organizations. And CIOs will need to be more focused on being chief coordinator of information organization across an organization, setting standards and guidelines based on input and focusing on providing the tools that will allow individuals to build and share personal depositories of information.

\section{CONCLUSION: MEMEX REDUX}

This idea of creating a shared system of interconnected individual information systems capable of forming a network of shared knowledge and wisdom is the culmination of a vision created over half a century ago by Vannever Bush [10]. From the scholar's workstation to hypertext and the worldwide web, Bush's vision has been a guiding metaphor for technology developments in education. Personal digital repositories linked together and easily shared would be the final step in realizing Bush's vision. For Bush, the answer to the information explosion was memex, a scholar's "mechanized private file and library," or in other words, a personal digital repository. A scholar's memex would in turn be linked to a network of scholars so that one scholar could pass information to "his friend for insertion in his own memex, there to be linked into the more general trail." Such a trail leads to effective management of information, starting with the individual and ending with collective knowledge and wisdom.

\section{REFERENCES}

1. Bible: Hebrew Ecclesiastes (1.XII.13) The Oxford Book of Verse in English Translation, Charles Tomlinson, ed.. Oxford University Press, 1980.

2. Bell, D. The Coming of Post-Industrial Society: A Venture in Social Forecasting. New York: Basic Books, 1973.

3. Lyman, P., and Varian, H. "How Much Information," 2003. Retrieved from http://www.sims.berkeley.edu/research/projects/how-much-info-2003/ on November 7, 2003.

4. Lynch, C. "Life after Graduation: Beyond the Academy." EDUCAUSE Review 38(5): 12-13, September/October, 2003.

5. Burns, C. "Three Mile Island: The Information Meltdown." in Horton, F.W. and D. Lewis, Great Information Disasters, 45-55. London: ASLIB, 1991.

6. Myburgh, S. "Strategic Information Management: Understanding a New Reality." The Information Management Journal 36(1): 36-43, January/February 2002. 
7. Ackoff, R. L. "Management Misinformation Systems." Management Sciences 14(4): B147-B156, 1967.

8. Nardi, B. and O'Day, V. L. Information Ecologies: Using Technology with Heart. Cambridge: MIT Press, 1999.

9. Davenport, T. H. Information Ecology. New York: Oxford University Press, 1997.

10. Bush, V. “As We May Think” Atlantic Monthly 176(00001): 101-108, July 1945.

\section{ABOUT THE AUTHOR}

Richard N. Katz is vice president of EDUCAUSE and Founding Director of the EDUCAUSE Center for Applied Research (ECAR). In nearly eight years at EDUCAUSE, Katz has been responsible for publications, communications, conferences and education, corporate relations, membership, R\&D, and information technology.

Before joining EDUCAUSE, Katz held a variety of management and executive positions spanning 14 years at the University of California (UC). As Executive Director of Business Planning and Practices, he was responsible for the design and implementation of many of the nine-campus UC system's strategic management initiatives. At UC, Katz was awarded the Gurevich Prize, the Olsten Award, and was the 2nd recipient of that University's Award for Innovative Management and Leadership.

Katz is the author, co-author or editor of six books and more than three dozen articles and monographs on a variety of management and technology topics. His book, Dancing with the Devil, was deemed one of the 10 most important education-related books of 1999 by Lingua Franca. His recent book, Web Portals in Higher Education, is being translated into Japanese by Tokyo University Press. Katz received his B.A. from the University of Pittsburgh, and his MBA from UCLA.

Paul B. Gandel is Vice Provost for Information Services and Dean of University Libraries at the University of Rhode Island and is a professor in the Graduate School of Library and Information Studies. As Chief Information Officer (CIO), Gandel is responsible for all aspects of information technology and information services-library services, computer services, voice and data networking, instructional technology services, and institutional research. His work at Rhode Island includes the development and management of a \$29 million initiative to upgrade the campus technology infrastructure. As part of this initiative, Gandel has overseen the upgrade of Rhode Island's entire communications network and the replacement of its administrative computing systems.

Before coming to the University of Rhode Island, Gandel was Associate Provost and Chief Information Officer at the Ohio University. Before Ohio, Gandel was Senior Director of Academic Computing and Associate Professor of Library Science at the University of North Texas, Supervisor of the Computing Technology Group at Bell Laboratories, Head of Media Services at the State University of New York at Plattsburgh, and Director of the Research Library at the Visual Studies Workshop in Rochester, New York. Gandel has made presentations and published on topics related to the management of information systems, library administration and services, software engineering, and visualization of information.

Dr. Gandel has a Ph.D. in Information Studies from Syracuse University, an M.A. in Library Science from the University of Wisconsin, and an M.F.A. in Photography and B.A. in History from the State University of New York at Buffalo. 